\title{
SACAROSE E ÁCIDO INDOLBUTÍRICO NO ENRAIZAMENTO DE Tectona grandis L.f.
}

\author{
Dayane Ávila Fernandes ${ }^{1}$, Diego Tyszka Martinez ${ }^{1}$, Reginaldo Brito da Costa ${ }^{1}$ \\ ${ }^{1}$ Universidade Federal de Mato Grosso - UFMT, Cuiabá - MT, E-mail: dayavila1@hotmail.com, diegotyszka@hotmail.com, \\ reg.brito.costa@gmail.com
}

\section{RESUMO}

O presente estudo objetivou testar a sacarose e o ácido indolbutírico (AIB) no enraizamento de microestacas de teca (Tectona grandis L.f.). As bases das microestacas foram imersas nas soluções e, em seguida, plantadas nos tubetes com substrato à base de casca de pinus bioestabilizada. $\mathrm{O}$ experimento foi dividido em três fases: casa de vegetação, casa de sombra e pleno sol. Foram avaliados: comprimento da parte aérea $(\mathrm{cm})$, diâmetro do colo $(\mathrm{cm})$ e peso da matéria fresca $(\mathrm{mg})$. Os resultados demonstraram haver interação entre cultivo e sacarose apenas na casa de vegetação (primeira avaliação) para as três variáveis analisadas. A concentração de AIB não apresentou diferença entre as avaliações e o uso de sacarose mostrou-se necessário principalmente quando houve sua redução no cultivo in vitro.

Palavras-chave: aclimatação, micropropagação, raízes

\section{INDOLE BUTYRIC ACID AND SUCROSE ON ROOTING OF Tectona grandis L.f.}

\begin{abstract}
This study aimed to test the sucrose and butyric acid (IBA) on rooting of teak (Tectona grandis L.f.). The bases of the microcuttings were immersed in the solutions, and then planted in tubes with substrate of pine bark. The experiment was divided into three phases: a greenhouse, shade and full sun. One evaluated: shoot length $(\mathrm{cm})$, diameter $(\mathrm{cm})$ and fresh weight $(\mathrm{mg})$. The results showed interaction between culture and sucrose only in the greenhouse (first test) for the three variables. The IBA concentration showed no difference between the evaluations and the use of sucrose was shown to be necessary especially when there was a reduction in vitro.
\end{abstract}

Keywords: acclimatization, micropropagation, roots 


\section{INTRODUÇÃO}

Dentre as técnicas de produção de mudas, a micropropagação ou propagação in vitro mostrou-se satisfatória, pois permite a produção massal de indivíduos com características genéticas desejáveis e alto padrão de sanidade das mudas, em um curto período de tempo (GRATTAPAGLIA \& MACHADO, 1998).

A cultura de tecidos vegetais envolve $\mathrm{o}$ processo onde pequenos fragmentos de tecido vivo (chamados de explantes) são isolados, desinfestados e cultivados assepticamente, por períodos indefinidos num meio de cultura apropriado (ANDRADE, 2002). Após esse processo de introdução e multiplicação, os explantes são submetidos à etapa de aclimatação que promoverá o endurecimento da muda para seu posterior plantio no campo.

A aclimatação é o processo pelo qual as plântulas produzidas em condições controladas são transferidas para um ambiente com condições naturais. As plântulas são expostas à redução de umidade do ar e temperatura instável, a fim de que possam suportar a transferência para o novo substrato e, posteriormente, sobreviver e se desenvolver (sem complicações) em condições naturais de campo (SILVA et al., 1995).
Essa passagem de um ambiente controlado do laboratório para o viveiro é considerada crítica e representa, em alguns casos, um fator limitante do processo de clonagem vegetal. As plantas produzidas in vitro passam de um estado com alta disponibilidade nutricional para uma condição autotrófica e, portanto precisam formar raízes rapidamente, para absorver os nutrientes necessários à sua sobrevivência. Como forma de otimizar o processo de micropropagação, a etapa de enraizamento in vitro pode ser substituída por um enraizamento ex vitro, no qual as partes aéreas produzidas são manipuladas como microestacas. O enraizamento ex vitro é desejável do ponto de vista econômico, pois há economia de espaço na sala de crescimento, energia elétrica e meio de cultura. Além disso, proporciona a produção de um sistema radicular mais completo e funcional, evitando assim a manipulação de plantas com raiz nua ou a poda de raízes, que são práticas que muitas vezes resultam em má qualidade no transplantio e até a morte das plântulas (GRATTAPAGLIA \& MACHADO, 1998).

Para acelerar a emissão de raízes, as bases das microestacas podem ser tratadas em soluções contendo auxina (regulador de crescimento que favorece a rizogênese). 
Conforme Vale et al. (2008), a presença de sacarose na solução de auxina representa uma fonte de energia necessária à divisão celular e emissão de raízes adventícias.

A importância dos carboidratos na emissão e formação de raízes vem sendo bem discutida. Reservas abundantes de carboidratos podem estar correlacionadas com maiores porcentagens de enraizamento e sobrevivência das plantas (FACHINELLO et al., 1995). Os níveis de sacarose devem ser mantidos em torno de $3 \%$, pois dessa forma, a planta acumularia reservas de carboidratos como fonte de energia para sobreviver no período de aclimatização. Para obter sucesso no desenvolvimento das plântulas, é necessário observar as concentrações do açúcar, pois estas influenciam diretamente nas reações fisiológicas das plantas (MOREIRA et al., 2007).

Concentrações elevadas de sacarose afetam de maneira considerável o desempenho fotossintético das plantas na transferência para o ambiente natural, ao passo que a ausência desse carboidrato é citada como a causa de elevadas taxas de mortalidade das plantas nessas condições (MALDANER et al., 2007).

Pio et al. (2003) constataram que a presença de sacarose (2\%) diluída na solução de AIB (2000 mg. $\mathrm{L}^{-1}$ ) no enraizamento de estacas apicais de figueira (Ficus carica), favoreceu o incremento da massa seca da parte aérea. Este resultado superou a melhor concentração de AIB de 4000 mg.L ${ }^{-1}$ sem utilização de sacarose, mostrando a possibilidade de utilização de uma concentração menor de auxina, fato esse considerado extremamente excepcional, pois do ponto de vista econômico, isso significa uma redução no custo final das mudas.

Neste contexto, a preocupação com relação tanto à qualidade quanto ao custo das mudas produzidas por meio da clonagem é crescente. As pesquisas são desenvolvidas buscando mudanças no ambiente de cultivo in vitro que visam a indução de maior grau de autotrofia dos tecidos vegetais para melhor adaptação e menor mortalidade no ambiente natural.

Muitos estudos abordam a fase crítica do transplantio, porém existe carência com relação a trabalhos sobre o período completo da aclimatação ao endurecimento de mudas produzidas através da micropropagação, é importante a comparação de experiências que mostram as dificuldades e soluções que podem ser encontradas nesse processo.

O presente estudo objetivou testar o uso de sacarose e as diferentes concentrações 
de ácido indolbutírico (AIB) no enraizamento ex vitro de microestacas de teca.

\section{MATERIAL E MÉTODOS}

$\mathrm{O}$ experimento foi instalado e conduzido no viveiro da Fazenda Panflora, pertencente à empresa Floresteca Agroflorestal S/A, situada no município de Jangada, Estado de Mato Grosso, no período de julho a setembro de 2011. A fazenda Panflora está inserida dentro do bioma Cerrado; geologicamente localizada na Depressão Cuiabana, área rebaixada, a uma latitude $15^{\circ} 14^{\prime} 08^{\prime \prime}$ sul e a uma longitude $56^{\circ} 29^{\prime} 21$ " oeste, estando a uma altitude de 178 metros acima do nível do mar.

A produção das mudas in vitro foi realizada no laboratório Bioteca Ltda. (situado no município de Várzea Grande, Mato Grosso, Brasil). Foi utilizado um tipo de clone de teca ( $T$. grandis) estabelecido in vitro, denominado como clone A (oriundo da Malásia e subcultivado in vitro por 5 anos). Os explantes foram cultivados por 35 dias em dois tipos de cultivo sendo, cultivo 1 (C1) com 18 g.L. $\mathrm{L}^{-1}$ de sacarose e tampa com filtro e cultivo 2 (C2) com 30 g. $\mathrm{L}^{-1}$ de sacarose e tampa sem filtro. Foram repicadas 1800 plântulas em 150 frascos contendo 12 explantes, sendo 75 frascos para cada tipo de cultivo.

Após o período de crescimento, as mudas foram preparadas para o envio ao viveiro. Primeiramente as plantas foram retiradas dos frascos e tiveram seus calos removidos com auxílio de tesoura, em seguida foram acondicionadas em caixas plásticas com $15 \mathrm{~cm}$ x $25 \mathrm{~cm}$ forradas com papel toalha, umedecidas com água destilada e forradas novamente com papel para permanecerem úmidas. As caixas foram separadas e identificadas de acordo com o cultivo.

No viveiro, os dois cultivos (C1 e C2) foram submetidos à presença/ausência de sacarose, diluída a 2\% em cinco concentrações do regulador de crescimento AIB $\left(0,0 ; 0,5 ; 1,0 ; 1,5\right.$ e 2,0 g. $\left.L^{-1}\right)$. O delineamento experimental foi em blocos casualizados em esquema fatorial $2 \times 2 \times 5$, considerando as duas formas de cultivo in vitro, a presença e ausência de sacarose e as cinco concentrações de AIB, totalizando vinte tratamentos em seis repetições, sendo que cada parcela experimental foi composta por 15 plantas.

As microestacas produzidas in vitro tiveram suas bases imersas nas soluções contendo AIB acrescidas ou não de sacarose, por cinco segundos e, em seguida, foram 
plantadas em tubetes contendo substrato à base de casca de pinos bioestabilizada.

No processo de aclimatização ex vitro, as plântulas passaram por três fases: casa de vegetação, casa de sombra e pleno sol. Ao final de cada uma dessas fases, foram retiradas 5 mudas de cada tratamento nos 6 blocos para a avaliação das seguintes variáveis: comprimento da parte aérea $(\mathrm{cm})$, diâmetro do colo $(\mathrm{cm})$ e peso da matéria fresca (mg). Para as medições foi utilizado um paquímetro digital e para a pesagem foi utilizada uma balança semi-analítica.

Os dados coletados foram submetidos à análise de variância e em seguida ao teste de médias. Para a comparação das médias entre os tratamentos utilizou-se o teste de Tukey a $5 \%$ de probabilidade. A análise foi realizada através do programa computacional Sistema para Análise de Variância - SISVAR.

\section{RESULTADOS E DISCUSSÃO}

$\mathrm{Na}$ fase de aclimatação e enraizamento houve divisão na avaliação entre as três etapas pelas quais as plântulas foram submetidas, sendo: casa de vegetação, casa de sombra e exposição a pleno sol. O levantamento de dados ocorreu na troca de um ambiente para o outro, ocorrendo enraizamento em todos os tratamentos testados.

De acordo com o resumo da análise de variância da primeira avaliação, houve interação significativa entre a sacarose (ausência e presença) e os cultivos (C1 e C2) para as três variáveis: comprimento de plântulas $(\mathrm{cm})$, diâmetro do colo $(\mathrm{cm})$ e peso da matéria fresca $(\mathrm{mg})$. Porém, não houve interação com as concentrações de AIB, que também não apresentaram diferença quando analisadas separadamente (Tabela 1).

Como, com relação ao uso de AIB, não houve diferença significativa entre as doses testadas, isto pode sugerir que a espécie possui níveis endógenos de auxina suficientes para realizar o enraizamento. Nesse sentido, Fermino Júnior et al. (2011) observaram pouca variação no crescimento do caule de teca com o uso de AIB independente da concentração $(0,100,1000$, 2000 e $4000 \mathrm{mg} \cdot \mathrm{L}^{-1}$ ), mostrando que o aumento da dose não influenciou no comprimento das plantas.

A mesma tendência foi observada para outras espécies; por Bosa et al. (2003), ao testar o efeito de AIB em cravo-de-amor (Gypsophila paniculata) e por Augusto et al. (2006) para a altura da parte aérea de amoreira-preta (Rubus idaeus L.). 
Tabela 1. Análise de variância para comprimento da parte aérea $(\mathrm{cm})$, diâmetro do colo $(\mathrm{cm}) \mathrm{e}$ peso da matéria fresca total $(\mathrm{mg})$ em mudas de Tectona grandis L.f. na casa de vegetação (avaliação 1), no município de Jangada, Estado de Mato Grosso, 2011.

\begin{tabular}{|c|c|c|c|c|}
\hline F.V. & GL & Comprimento & $\begin{array}{c}\text { Diâmetro } \\
\text { do colo }\end{array}$ & $\begin{array}{c}\text { Peso da matéria } \\
\text { fresco }\end{array}$ \\
\hline Bloco & 5 & $0,77^{\mathrm{ns}}$ & $16,15 * *$ & $0,92^{\mathrm{ns}}$ \\
\hline Cultivo (C) & 1 & $2,63^{\mathrm{ns}}$ & $18,88 * *$ & $0,10^{\mathrm{ns}}$ \\
\hline Sacarose (S) & 1 & $1,78^{\mathrm{ns}}$ & $0,001^{\mathrm{ns}}$ & $1,48^{\mathrm{ns}}$ \\
\hline AIB (A) & 4 & $0,13^{\mathrm{ns}}$ & $0,36^{\mathrm{ns}}$ & $1,57^{\mathrm{ns}}$ \\
\hline $\mathrm{S} \times \mathrm{C}$ & 1 & $6,29 *$ & $5,14 *$ & $13,45 * *$ \\
\hline$A \times C$ & 4 & $0,39^{\mathrm{ns}}$ & $1,03^{\mathrm{ns}}$ & $1,77^{\mathrm{ns}}$ \\
\hline$A \times S$ & 4 & $0,60^{\mathrm{ns}}$ & $0,54^{\mathrm{ns}}$ & $0,36^{\mathrm{ns}}$ \\
\hline$A \times S \times C$ & 4 & $0,50^{\mathrm{ns}}$ & $0,10^{\mathrm{ns}}$ & $0,22^{\mathrm{ns}}$ \\
\hline Resíduo & 95 & & & \\
\hline $\mathrm{CV}(\%)$ & & 12,485 & 31,753 & 34,438 \\
\hline
\end{tabular}

Vários autores descrevem a necessidade da utilização de auxinas no enraizamento de espécies cultivadas in vitro. Neste caso o que se pode constatar é que não houve diferença entre as concentrações de AIB testadas, inclusive a ausência $\left(0\right.$ g. $\left.\mathrm{L}^{-1}\right)$ não afetou a adaptação ao ambiente natural. Essa ocorrência, provavelmente, se deve à facilidade de enraizamento, o que também condiz com os resultados encontrados por Augusto et al. (2006).

Conforme Assis e Teixeira (1998) existem várias evidências de que a rizogênese é geneticamente controlada; isso pode ser observado entre espécies, cultivares e clones e está relacionada à habilidade natural de formação de raízes.

Para a variável comprimento da parte aérea $(\mathrm{cm})$, a presença de sacarose mostrouse melhor no $\mathrm{C} 1$ e a ausência, no $\mathrm{C} 2$, (Tabela 2).

Constata-se que a adição de sacarose foi necessária no cultivo em que houve redução desse nutriente e dispensada no cultivo convencional, independente da concentração de AIB. 
Tabela 2. Comprimento da parte aérea $(\mathrm{cm})$ de mudas de Tectona grandis L.f. submetidas a diferentes cultivos e ausência/presença de sacarose, aclimatadas em casa de vegetação no município de Jangada, Estado de Mato Grosso, 2011.

\begin{tabular}{ccc}
\hline Sacarose & \multicolumn{2}{c}{ Cultivo } \\
\cline { 2 - 3 } & $\mathrm{C} 1$ & $\mathrm{C} 2$ \\
\hline Presença & $52,58 \mathrm{Aa}^{*}$ & $47,78 \mathrm{Ba}$ \\
Ausência & $51,22 \mathrm{Ab}$ & $52,24 \mathrm{Aa}$ \\
\hline
\end{tabular}

* Médias seguidas pela mesma letra não diferem estatisticamente entre si pelo teste de Tukey a $5 \%$ de probabilidade. Letras maiúsculas referem-se às colunas e letras minúsculas, às linhas. $\mathrm{C} 1=$ cultivo 1 e $\mathrm{C} 2=$ cultivo 2 .

O estado nutricional exerce grande influência no enraizamento, uma vez que o processo de iniciação radicular requer energia. A maior influência dos carboidratos está ligada à relação carbono/nitrogênio, portanto a aplicação exógena de açúcares e amido pode favorecer essa relação (ASSIS \& TEIXEIRA, 1998).

Em experimento com figueira (Ficus carica), Pio et al. (2003) encontraram melhores resultados para a variável massa seca das brotações quando se utilizou a sacarose $2 \%$ diluídas em $2000 \mathrm{mg} . \mathrm{L}^{-1}$ de AIB e observaram ainda ter ocorrido redução da melhor concentração de AIB sem o uso de sacarose (4000 mg. $\left.\mathrm{L}^{-1}\right)$. Esse resultado mostrou que é possível reduzir as concentrações de AIB ao utilizar sacarose na solução, contribuindo na redução do custo final das mudas.

Os melhores resultados para $o$ diâmetro do colo $(\mathrm{cm})$ foram obtidos na presença de sacarose para os dois cultivos e a ausência no C2 (Tabela 3).

De maneira similar observou-se que a adição de sacarose foi necessária no $\mathrm{Cl}$ $(0,60 \mathrm{~cm})$, porém dessa vez, também foi importante no $\mathrm{C} 2(0,68 \mathrm{~cm})$, que ainda respondeu de maneira satisfatória na ausência de sacarose $(0,76 \mathrm{~cm})$, todos independentes da concentração de AIB.

Para a formação de raízes é necessária energia que pode ser oriunda da fotossíntese ou de outra fonte de açúcar. O carbono exógeno no meio de cultivo serve como fonte de energia, influenciando na fisiologia da planta, diferenciação e crescimento dos tecidos e órgãos. Além disso, vale ressaltar que altas concentrações de sacarose no cultivo in vitro favorece o acúmulo de carboidratos no tecido devido a síntese reduzida dos açúcares (CALVETE et al., 2002). 
Tabela 3. Diâmetro do colo $(\mathrm{cm})$ de mudas de Tectona grandis L.f. submetidas a diferentes cultivos e ausência/presença de sacarose, aclimatadas em casa de vegetação no município de Jangada, Estado de Mato Grosso,2011.

Sacarose Cultivo

\begin{tabular}{ccc}
\hline Sacarose & \multicolumn{2}{c}{ Cultivo } \\
\cline { 2 - 3 } & $\mathrm{C} 1$ & $\mathrm{C} 2$ \\
\hline Presença & $0,60 \mathrm{Aa}^{*}$ & $0,68 \mathrm{Aa}$ \\
Ausência & $0,51 \mathrm{Ab}$ & $0,76 \mathrm{Aa}$ \\
\hline
\end{tabular}

* Médias seguidas pela mesma letra não diferem estatisticamente entre si pelo teste de Tukey a $5 \%$ de probabilidade. Letras maiúsculas referem-se às colunas e letras minúsculas, às linhas. $\mathrm{C} 1=$ cultivo 1 e $\mathrm{C} 2=$ cultivo 2 .

A presença de sacarose na solução de AIB provavelmente foi necessária para complementar o fornecimento de energia utilizada no enraizamento.

Para a variável matéria fresca (mg), novamente a presença de sacarose mostrouse melhor no $\mathrm{C} 1$, e a ausência no C2 (Tabela 4).

Este resultado foi semelhante ao comprimento da parte aérea e também ao diâmetro do colo, cujos resultados mostraram que os dois tratamentos trouxeram benefícios para o desenvolvimento em todas as variáveis analisadas.

A concentração menor de sacarose no $\mathrm{C} 1 \mathrm{fez}$ com que as plantas necessitassem de uma fonte externa para complementar a energia necessária para o seu desenvolvimento, no $\mathrm{C} 2$ (convencional) a quantidade de açúcar fornecido in vitro mostrou-se suficiente.

$\mathrm{O}$ acréscimo da concentração de $\mathrm{CO}_{2}$ que foi proporcionado no $\mathrm{C} 1$, possivelmente pelo uso da vedação com filtro, promoveu o aumento da fotossíntese, em função de seu efeito direto sobre a enzima Rubisco (Ribulose 1,5 difosfato carboxilase) (ARIGITA et al., 2002). Com isso houve maior gasto de energia e, provavelmente, explica a necessidade de complementar com sacarose exógena na aclimatação.

De acordo com o resumo da análise de variância na segunda avaliação, não houve interação significativa entre os fatores testados. Separadamente, os cultivos (C1 e C2) apresentaram diferença estatística para o comprimento $(\mathrm{cm})$ e diâmetro do colo $(\mathrm{cm}) \mathrm{e}$ a sacarose (ausência e presença), para a variável peso da matéria fresca $(\mathrm{mg})$. Além disso, não foi observada diferença entre as concentrações de AIB (Tabela 5).

$\mathrm{Na}$ segunda avaliação não houve interação significativa para nenhum dos fatores. Analisando separadamente, os cultivos apresentaram diferença no comprimento e diâmetro do colo e a sacarose para o peso da matéria fresca. 
Tabela 4. Peso da matéria fresca $(\mathrm{mg})$ de mudas de Tectona grandis L.f. submetidas a diferentes cultivos e ausência/presença de sacarose, aclimatadas em casa de vegetação no município de Jangada, Estado de Mato Grosso, 2011.

\begin{tabular}{ccc}
\hline Sacarose & \multicolumn{3}{c}{ Cultivo } \\
\cline { 2 - 3 } & $\mathrm{C} 1$ & $\mathrm{C} 2$ \\
\hline Presença & $0,69 \mathrm{Aa}^{*}$ & $0,53 \mathrm{Bb}$ \\
Ausência & $0,59 \mathrm{Ab}$ & $0,73 \mathrm{Aa}$ \\
\hline
\end{tabular}

* Médias seguidas pela mesma letra não diferem estatisticamente entre si pelo teste de Tukey a $5 \%$ de probabilidade. Letras maiúsculas referem-se às colunas e letras minúsculas, às linhas. $\mathrm{C} 1=$ cultivo 1 e $\mathrm{C} 2=$ cultivo 2 .

Tabela 5. Análise de variância para comprimento da parte aérea $(\mathrm{cm})$, diâmetro do colo $(\mathrm{cm})$ e peso da matéria fresca (mg) em mudas de Tectona grandis L.f. na casa de sombra (avaliação 2), no município de Jangada, Estado de Mato Grosso, 2011.

\begin{tabular}{|c|c|c|c|c|}
\hline F.V. & GL & Comprimento & $\begin{array}{l}\text { Diâmetro } \\
\text { do colo }\end{array}$ & $\begin{array}{l}\text { Peso da matéria } \\
\text { fresca }\end{array}$ \\
\hline Bloco & 5 & $8,65 * *$ & $4,48 * *$ & $12,61 * *$ \\
\hline Cultivo (C) & 1 & $4,87 * *$ & $5,44 *$ & $0,01^{\mathrm{ns}}$ \\
\hline Sacarose (S) & 1 & $1,86^{\mathrm{ns}}$ & $0,31^{\mathrm{ns}}$ & $6,12 * *$ \\
\hline $\operatorname{AIB}(\mathrm{A})$ & 4 & $1,50^{\mathrm{ns}}$ & $0,59^{\mathrm{ns}}$ & $0,33^{\mathrm{ns}}$ \\
\hline $\mathrm{S} \times \mathrm{C}$ & 1 & $0,04^{\mathrm{ns}}$ & $0,001^{\text {ns }}$ & $0,94^{\mathrm{ns}}$ \\
\hline $\mathrm{A} \times \mathrm{C}$ & 4 & $0,61^{\mathrm{ns}}$ & $0,35^{\mathrm{ns}}$ & $0,14^{\mathrm{ns}}$ \\
\hline Ax S & 4 & $0,19^{\mathrm{ns}}$ & $0,43^{\mathrm{ns}}$ & $0,45^{\mathrm{ns}}$ \\
\hline $\mathrm{A} \times \mathrm{S} \times \mathrm{C}$ & 4 & $0,71^{\mathrm{ns}}$ & $0,35^{\mathrm{ns}}$ & $1,25^{\mathrm{ns}}$ \\
\hline Resíduo & 95 & & & \\
\hline CV (\%) & 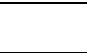 & 11,765 & 14,666 & 29,753 \\
\hline
\end{tabular}

O melhor resultado para o de grande importância nos processos comprimento foi obtido no cultivo 1 e para o metabólicos e na composição da parede diâmetro do colo no cultivo 2 (Tabela 6). A celular (PASQUAL, 2001), sendo essencial quantidade de sacarose no cultivo in vitro ao crescimento.

afeta a produção de metabólitos secundários 
Tabela 6. Comprimento da parte aérea $(\mathrm{cm})$ e diâmetro do colo $(\mathrm{cm})$ de mudas de Tectona grandis L.f. submetidas a diferentes cultivos, aclimatadas em casa de sombra no município de Jangada, Estado de Mato Grosso.

\begin{tabular}{ccc}
\hline \multirow{2}{*}{ Cultivo } & \multicolumn{2}{c}{ Variáveis } \\
\cline { 2 - 3 } $\mathrm{C} 1$ & $62,02 \mathrm{~A}^{*}$ & Diâmetro do colo $(\mathrm{cm})$ \\
$\mathrm{C} 2$ & $59,15 \mathrm{~B}$ & $1,92 \mathrm{~B}$ \\
\hline
\end{tabular}

* Médias seguidas pela mesma letra não diferem estatisticamente entre si pelo teste de Tukey a 5\% de probabilidade. $\mathrm{C} 1=$ cultivo 1 e $\mathrm{C} 2=$ cultivo 2 .

De acordo com Skrebsky et al. (2004), a nutrição exclusivamente autotrófica, induzida in vitro, nem sempre conduz a melhor crescimento das plantas quando comparado com aquele obtido em meio de cultivo contendo sacarose. Esses autores afirmam que há influência positiva da sacarose no crescimento das plantas mesmo que se tenha enriquecido o ambiente com $\mathrm{CO}_{2}$.

Para a variável matéria fresca $(\mathrm{mg})$, a ausência de sacarose mostrou-se melhor para o crescimento nessa fase (Tabela 7).

A ausência de sacarose mostrou-se superior para a formação de matéria fresca das plântulas em comparação ao tratamento utilizando sacarose exógena. Provavelmente as reservas de carboidratos nos tecidos estavam mais elevadas nessa fase devido a realização de fotossíntese.

Ao contrário do encontrado por Pio et al. (2003), que observaram que a presença de sacarose exógena proporcionou melhores resultados em figueira (Ficus spp. ) para as variáveis comprimento da maior raiz $(6,49$ $\mathrm{cm})$ e massa seca das raízes $(157,13 \mathrm{mg})$.

Dentre os fatores que podem influenciar o enraizamento e posterior desenvolvimento, estão tanto os intrínsecos, relacionados à própria planta, quanto os extrínsecos, relacionados às condições ambientais (NORBERTO et al., 2001).

$\mathrm{Na}$ terceira avaliação, realizada ao final do período de rustificação, não houve diferença significativa em nenhum dos fatores testados para nenhuma das variáveis analisadas (Tabela 8).

Esses resultados mostraram que no cultivo in vitro, os efeitos da imersão ou não no regulador de crescimento AIB independente da dose, bem como o uso ou não de sacarose têm influência apenas nas etapas iniciais do processo de aclimatação, período crítico no qual a plântula sofre as mudanças bruscas pelo transplante do ambiente in vitro para o ex vitro. 
Tabela 7. Peso da matéria fresca $(\mathrm{mg})$ de mudas de Tectona grandis L.f. submetidas a presença/ausência de sacarose, aclimatadas em casa de sombra no município de Jangada, Estado de Mato Grosso.

\begin{tabular}{lc}
\hline Sacarose & Peso $(\mathrm{mg})$ \\
\hline Presença & $0,85 \mathrm{~B}$ \\
Ausência & $0,98 \mathrm{~A}$ \\
\hline
\end{tabular}

* Médias seguidas pela mesma letra não diferem estatisticamente entre si pelo teste de Tukey a $5 \%$ de probabilidade.

Tabela 8. Resumo da análise de variância para comprimento da parte aérea $(\mathrm{cm})$, diâmetro do colo $(\mathrm{cm})$ e peso da matéria fresca $(\mathrm{mg})$ em mudas de Tectona grandis L.f. no pleno sol (avaliação 3), no município de Jangada, Estado de Mato Grosso.

\begin{tabular}{|c|c|c|c|c|}
\hline F.V. & GL & Comprimento & $\begin{array}{c}\text { Diâmetro } \\
\text { do colo }\end{array}$ & $\begin{array}{c}\text { Peso da matéria } \\
\text { fresca }\end{array}$ \\
\hline Bloco & 5 & $6,81 * *$ & $8,07 * *$ & $5,20 *$ \\
\hline Cultivo (C) & 1 & $0,66^{\mathrm{ns}}$ & $2,13^{\mathrm{ns}}$ & $0,14^{\mathrm{ns}}$ \\
\hline Sacarose (S) & 1 & $1,42^{\mathrm{ns}}$ & $0,04^{\mathrm{ns}}$ & $0,16^{\mathrm{ns}}$ \\
\hline AIB (A) & 4 & $0,52^{\mathrm{ns}}$ & $0,57^{\mathrm{ns}}$ & $0,98^{\mathrm{ns}}$ \\
\hline $\mathrm{S} \times \mathrm{C}$ & 1 & $0,16^{\mathrm{ns}}$ & $0,16^{\mathrm{ns}}$ & $0,74^{\mathrm{ns}}$ \\
\hline $\mathrm{A} \times \mathrm{C}$ & 4 & $0,60^{\mathrm{ns}}$ & $1,08^{\mathrm{ns}}$ & $0,49^{\mathrm{ns}}$ \\
\hline$A \times S$ & 4 & $2,04^{\mathrm{ns}}$ & $1,78^{\mathrm{ns}}$ & $1,00^{\mathrm{ns}}$ \\
\hline$A \times S \times C$ & 4 & $1,87^{\mathrm{ns}}$ & $0,99^{\mathrm{ns}}$ & $0,60^{\mathrm{ns}}$ \\
\hline Resíduo & 95 & & & \\
\hline CV $(\%)$ & & 8,2041 & 8,1801 & 21,854 \\
\hline
\end{tabular}

Segundo Grattapaglia e Machado (1998), a rizogênese ocorre no período de uma a três semanas, e pode ser dividida em: indução, iniciação e alongamento de raízes. Os autores afirmaram ainda que as duas primeiras fases respondem ou dependem da presença da auxina, sendo que no crescimento pode haver inibição em relação à presença do regulador. 
Ainda segundo Castro et al. (2005), aplicações exógenas de auxina podem promover a iniciação e o desenvolvimento radicular precoce. Todavia, as mesmas concentrações que ajudam a estimular o surgimento das raízes, podem inibir seu posterior crescimento.

\section{CONCLUSÕES}

As concentrações de AIB não tiveram diferença em nenhuma das fases analisadas, o que sugere que outros fatores podem influenciar o enraizamento $\mathrm{e}$ adaptação ex vitro de Tectona grandis.

A interação entre a sacarose e o tipo de cultivo mostrou efeito apenas na primeira fase do experimento, em casa de vegetação.

\section{REFERÊNCIAS BIBLIOGRÁFICAS}

ANDRADE, S. R. M. 2002. Princípios da cultura de tecidos vegetais. Planaltina: Embrapa Cerrados, $16 \mathrm{p}$.

ARIGITA, L.; GONZÁLEZ, A.; TAMÉS, R.S. 2002. Influence of $\mathrm{CO}_{2}$ and sucrose on photosynthesis and transpiration of Actinidia deliciosa explants cultured in vitro. Physiologia Plantarum, Copenhagen, v. 115, p. 166-173.

ASSIS, T. F.; TEIXEIRA, S. L. 1998. Enraizamento de plantas lenhosas. In: TORRES, A.; CALDAS, L. S.; BUSO, J. A. Cultura de tecidos e transformação genética de plantas. Brasília: Embrapa-SPI/ Embrapa CNPH, v. 1, p. 261-296.
AUGUSTO, C. S. S.; BIASI, L. A.; TELLES, C. A. 2006. Enraizamento e aclimatização de plantas micropropagadas de amoreira-preta $\mathrm{cv}$. Brazos. Revista Brasileira de Fruticultura, Jaboticabal, v. 28 n. 3, p. 473-476, dez.

BOSA, N.; CALVETE, E. O.; NIENOW, A. A.; SUZIN, M. 2003. Enraizamento e aclimatização de plantas micropropagadas de gipsófila. Horticulura Brasileira, Brasília, vol. 21 n. 2.

CALDEIRA, S. F.; OLIVEIRA, D. L. C. 2008. Desbaste seletivo em povoamentos de Tectona grandis com diferentes idades. Acta Amazônica, Manaus, v. 38, n. 2.

CALVETE, E. O.; KÄMPF, A. N.; SUZIN, M. 2002. Concentração de sacarose no enraizamento in vitro de morangueiro. Horticultura Brasileira, Brasília, v. 20, n. 2, p. 186-191.

CASTRO, P. R. C.; KLUGE, R. A.; PERES, L. E. P. 2005. Manual de fisiologia vegetal: teoria e prática. Piracicaba: Editora Agronômica Ceres, $650 \mathrm{p}$.

FACHINELLO, J. C.; HOFFMANN, A.; NACHTIGAL, J. C.; KERSTEN, E.; FORTES, G. R. L. 1995. Propagação de plantas frutíferas de clima temperado. 2ed. Pelotas: UFPel, 178p.

FERMINO JUNIOR, P. C. P.; RAPOSO, A.; SCHERWINSKI-PEREIRA, J. E. 2011. Enraizamento ex vitro e aclimatação de plantas micropropagadas de Tectona grandis. FLORESTA, Curitiba, PR, v. 41, n. 1, p. 79-86.

FERREIRA, D. F. 2000. Análise estatística por meio do SISVAR (Sistema para Análise de Variância) para Windows versão 4.0. In: REUNIÃO ANUAL DA REGIÃO BRASILEIRA DA SOCIEDADE INTERNACIONAL DE BIOMETRIA, 45., 2000, São Carlos. Anais... São Carlos: UFSCar, p. 255258. 
GRATTAPAGLIA, D.; MACHADO, M. A. 1998. Micropropagação. In: TORRES, A. C.; CALDAS, L. S.; BUSO, J. A. Cultura de tecidos e transformação genética de plantas. Brasília: Embrapa - SPI / Embrapa - CNPH, v. 1, p. 183260.

MALDANER, J.; NICOLOSO, F. T.; SANTOS, E. S.; FAGUNDES, C. K.; FLORES, R.; JUCOSKI, G. O.; SKREBSKY, E. C. 2007. Crescimento de plântulas de Pfaffia glomerata (Spreng.) Pedersen cultivadas in vitro sob dois níveis de nitrogênio e sacarose, durante seis subculturas sucessivas e aclimatização. Ciência Rural, Santa Maria, v. 37, n. 1.

MOREIRA, B. M. T.; TOMBA, E. C.; ZONETTI, P.C. 2007. Crescimento in vitro de plântulas de orquídea (Laelia purpurata Lindl var. venosa X Cattleya warneri T. Moore alba) sob diferentes concentrações de sacarose e frutose. Sábios - Revista Saúde e Biologia, Campo Mourão, v. 2, n. 2, p. 16-21.

NORBERTO, P. M.; CHALFUN, N. N. J.; PASQUAL, M.; VEIGA, R.L.; PEREIRA, G. E.; MOTA, J. H. 2001. Efeito da época de estaquia e do AIB no enraizamento de estacas de figueira (Ficus carica L.). Ciência e Agrotecnologia, Lavras, v. 25, n. 3, p. 533-541.

PASQUAL, M. 2001. Introdução: fundamentos básicos. In: Curso de especialização à distância cultura de tecidos vegetais (CTV). Lavras: UFLA/FAEPE, 97p.

PIO, R.; RAMOS, J. D.; CHALFUN, N. N. J.; COELHO, J. H. C.; GONTIJO, T. C. A.; CARRIJO, E. 2003. Enraizamento de estacas apicais de figueira tratadas com sacarose e ácido indolbutírico por imersão rápida. Revista Brasileira Agrociência, v. 9, n. 1, p. 35-38.
SILVA, A. T.; PASQUAL, M.; ISHIDA, J. S.; ANTUNES, L. E. C. 1995. Aclimatação de plantas provenientes da cultura in vitro. Pesquisa Agropecuária Brasileira, Brasília, v. 30, n. 01, p. 4953.

SKREBSKY, E. C.; NICOLOSO, F. T.; FERRÃO, G. E. 2004. Sacarose e período de cultivo in vitro na aclimatação ex vitro de ginseng brasileiro (Pfaffia glomerata Spreng. Pedersen). Ciência Rural, Santa Maria, v. 34, n. 5, p. 1471-1477.

VALE, M. R.; CHALFUN, N. N. J.; MENDONÇA, V.; MIRANDA, C. S.; COELHO, G. V. A. 2008. Ácido indolbutírico e sacarose no enraizamento de estacas de goiabeira Cultivar Paluma. Caatinga (Mossoró Brasil), v. 21, n. 3, p. 69-74, jun./ago. 2008.

Recebido em:10\07\2014 Aceito para publicação em:29\05\2015 